\title{
Exposure to Video Games Shortens Simple Visual Reaction Time: A Study in Indian School Children
}

\author{
Paramita Bhattachariyya ${ }^{1}$, Subhasis Das ${ }^{1 *}$ and Ashwin R. ${ }^{2}$ \\ ${ }^{1}$ Dept. of Physiology, Pondicherry Institute of Medical Sciences, Kalapet, Puducherry, India \\ ${ }^{2}$ Dept. of General Surgery, Madurai Medical College, Alwarpuram, Madurai, Tamil Nadu, India
}

\begin{abstract}
Background: Electronic gaming media has become an integral part of the lives of school children. Previous research suggested that action video game playing improves cognitive performance, leading to better visual and attentional skills. On the contrary, other studies have concluded that such gaming activities are more likely to have multiple ill effects on the psychological and physical health of young adults. Visual reaction time has already served to be a good indicator of aptitude in sports involving quick reflexes. However, there is insufficient knowledge about the effects of gaming media exposure on cognitive patterns, as assessed by visual reaction time, especially in Indians. Hence this study was undertaken to estimate the effect of the usage of electronic gaming media on the simple visual reaction time of Indian school children.
\end{abstract}

Methods: Healthy male school-going children in the age group 9-12 years, who were frequently exposed to electronic gaming media for not less than 7-9 hours per week along with children who did not play video games but had normal physical activity ( $\mathrm{n}=38$ in each group) were included in this study. Visual reaction time, using a red light, was estimated in the participants.

Result: Visual reaction time was found to be significantly decreased in children who played computer games regularly, as compared to controls. A significant negative correlation was also seen, in the study group, between visual reaction time and duration of hours of playing games.

Conclusion: Thus, this study concludes that video game playing improves performance in tasks involving hand-eye coordination and quick reflexes.

Keywords: Action Video Games, Visual Reaction Time, Hand-Eye Coordination, Attentional Skills,

\section{Introduction}

In the 1970s and ' 80 s video game parlors and arcades first came into existence and soon became a favorite pastime for adolescents and adults. With the turn of the century, the popularity of these games has spread among children also. This was made possible by the advent of computer games, gaming consoles and gaming apps on tablets and mobile phones, which have brought these apparently risk-free, often action-packed entertainment right into our homes. Devices using virtual reality have taken the gaming experience into an entirely different level. With the availability of online gaming environments video game players (VGPs) have even begun to compete over the internet and the social aspect of such gaming has also got enhanced. In the industrialized countries, the incidence of exposure to these gaming media, among children aged 9 to 16 years, ranges from $98 \%$ to $100 \%$. [1] The average media consumption of the children in this age group is $>4$ hours/day.[2]

Most evaluations have focused on the negative influence of excessive media consumption on child health. There has been a lot of speculation by many health professionals across the globe claiming that these gaming media are the major cause for the development of childhood obesity, impulsivity and aggressive behavior. Studies in Germany and Romania have demonstrated that prolonged exposure to computer games have negative influences on sleep, learning and memory, leading to many psychiatric symptoms especially emotional and behavioral symptoms, somatic complaints and family interaction problems.[3,4] In a study correlating cognitive skills with neuro-psychiatric behavior, Chinese children exhibited more impulsivity and various psychiatric disorders including anxiety, depression and poor interpersonal relations.[5] Excessive internet usage has been shown to be associated with Attention Deficit Hyperactivity Disorder (ADHD).[6] Online game addiction in school children has shown positive correlation with aggressiveness and narcissistic personality traits which may predispose to hostile behavior, frequent arguments with teachers and poor school performance.[7,8] A study conducted on Spanish school children reported that chronic exposure to video games gives rise to distress in social life, occupational activities and school performance.[9] 
Behavioral health aside, on the physical aspect also, changes have been reported in VGPs, obesity and visual impairments being the most common of these.

Despite the gamut of studies highlighting the negative aspects of video games on behavior, much research has gone into examining the cognitive augmentation that VGPs exhibit. Visuospatial experience and the prolonged engagement in a demanding visual task, obtained through playing action video games, enhances several visual and cognitive processes.[10]

Playing action-video-games can alter fundamental characteristics of the visual system, such as the spatial resolution of visual processing across the visual field. [11] Action games not only widen the range of cognitive abilities, including attention, memory, and executive control skills, but also significantly improve eye-hand motor co-ordination. $[12,13]$ There may be an enhancement in attentional skills in VGPs [14] and such avid players of these fast paced video games demonstrate better target detection capabilities when given attention-demanding tasks.[15] A significant reduction in reaction times has also been reported.[16]

Reviewing the literature, it was found that despite the enormous progress in research done across the world to assess the impact of these electronic gaming media on the health status of school children, opinion is divided between the negative and the positive aspects. Also, there is insufficient knowledge about the effects of excessive media exposure on simple reaction times in Indian children, a deficit that this study has sought to rectify.

\section{Materials and Methods}

This observational study was initiated after obtaining due approval from the Institutional Research Committee (Review Board) and Ethics Committee. The study was conducted in two groups, with 38 healthy male children, in the age group 9-12 years, randomly selected from schools in and around Pondicherry, as per selection criteria. Children in the "study group" played computer games for not less than 7-9 hours/week, while those in the "control group" did not play computer games but had normal physical activity. Children with history of visual or auditory impairment, epilepsy, ADHD, mental retardation or any other psychiatric disorder were excluded. Children with history suggestive of eye, ear, and throat infections, at the time of the study, were also excluded.

Variables such as the time of the day for the tests, ambient temperature, humidity and posture of the participant in relation to the apparatus were constant for all the participants. Other constants ensured were freedom from exams or tests, adequate sleep on the night prior to the testing and a normal breakfast the same morning.

After obtaining permission from the school authorities, informed written consent from the parents of each recruited child, and assent from each of the children, all the participants underwent a thorough physical examination, including tests for vision with torch, Snellen's chart, Jaeger's chart and Ishihara's charts and tests of hearing using tuning forks, prior to starting the procedure. With help of the parents of the recruited children and their teachers, a questionnaire, with relevant demographic and anthropometric data and data related to video game playing, was filled up.

Audio-visual Reaction time apparatus (Anand Agencies, Pune) was used for the measurement of reaction time. Each participant had to undergo 5 sets of 10 recordings of simple visual reaction time using a red-light test stimulus, with a 1 minute break in between sets. The mean of the 50 recordings from each subject was used for analysis.

\section{Result}

For the purpose of statistical analysis, GraphPad Prism 4 software package was used. Statistical significance was considered at a $\mathrm{p}$ value $<0.05$.

The mean values of anthropometric variables such as age, height, weight and BMI were statistically similar between the two groups, i.e., the study group $(n=38)$ and the control $(\mathrm{n}=38)$. (Table-1)

The mean simple visual reaction times of the participants in the study group and control group were $157.4 \pm 21.9$ $\mathrm{ms}$ and $218.8 \pm 36.14 \mathrm{~ms}$ respectively. Comparison of the mean simple visual reaction times in the two groups by unpaired 2 tailed Student " $\mathrm{t}$ " test showed a statistically significant difference $(\mathrm{p}<0.0001)$. (Fig.-1)

Among the participants in the study group, the mean duration of video game playing was $6.59 \pm 3.59$ hours per week. A significant negative correlation (Pearson) between visual reaction time and duration of hours of playing games was observed in the study group participants $(\mathrm{r}=$ $-0.0381, \mathrm{p}<0.05$ ). (Fig.-2) On analysis of the correlation between reaction time and BMI, no statistically significant correlation was observed in either group.

\section{Discussion}

This observational study aimed at assessing the effect of video game playing on simple visual reaction time, showed that there was a statistically significant decrease in visual reaction time in children playing computer games $(p<0.0001)$ as compared to controls. The results of this study are consistent with the earlier finding that action 
Table 1: Comparison of anthropometric parameters between Study and Control groups.

\begin{tabular}{|l|c|c|c|} 
& Study group (Mean \pm SD) & Control (Mean \pm SD) & p \\
\hline Age $(\mathrm{yrs})$ & $12.26 \pm 0.95$ & $12.42 \pm 0.86$ & $>0.05$ \\
\hline Height $(\mathrm{cm})$ & $149 \pm 8.33$ & $146.24 \pm 8.36$ & $>0.05$ \\
\hline Weight $(\mathrm{kg})$ & $40.53 \pm 9.29$ & $37.97 \pm 6.28$ & $>0.05$ \\
\hline BMl $(\mathrm{kg} / \mathrm{m} 2)$ & $17.68 \pm 3.59$ & $17.24 \pm 1.92$ & $>0.05$ \\
\hline
\end{tabular}

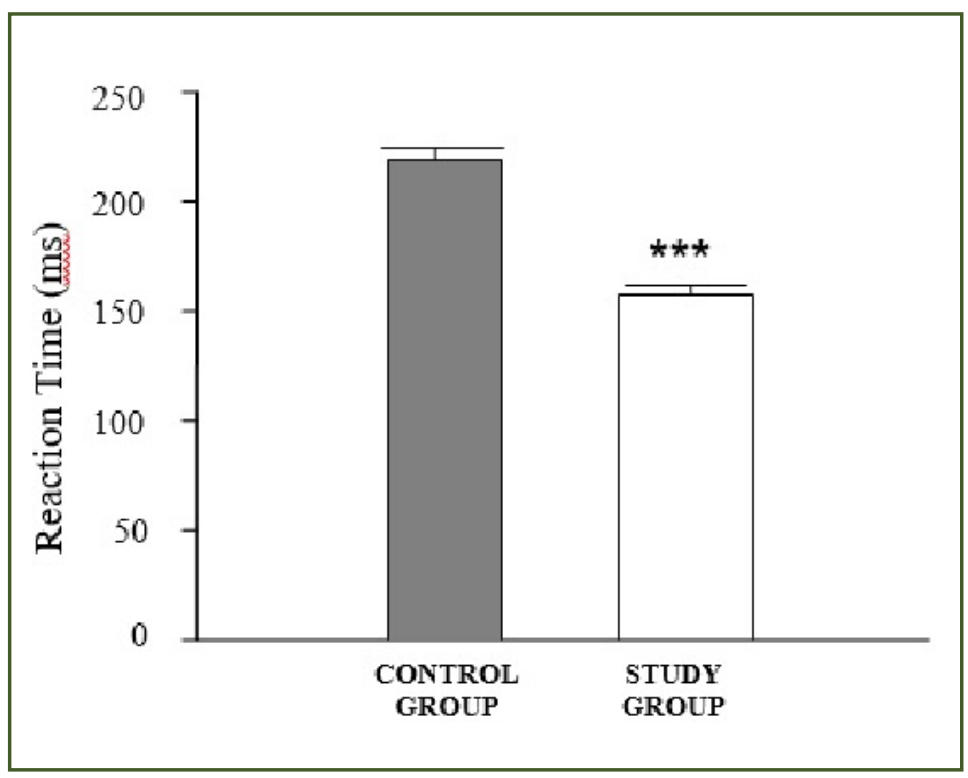

Fig. 1: Comparison of simple visual reaction time Between the Study and Controls groups.

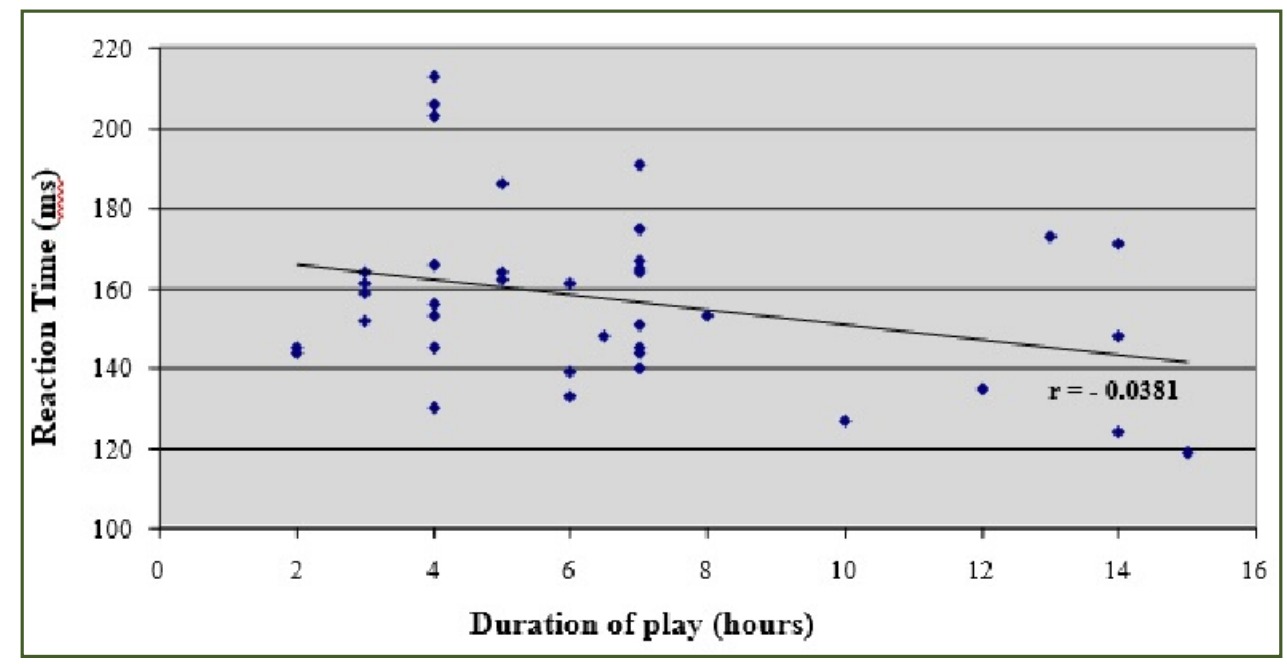

Fig.-2: Correlation between reaction time and duration of playing video games among Study group participants.

video games modify visual selective attention, leading to improvement in basic cognitive skills.[12]

A decrease in reaction time indicates an improved sensorimotor performance and could be due to an enhanced information processing ability of the central nervous system.[17] However, the underlying mechanisms for this improvement remains unclear. It has been suggested that alterations in visual skills such as those brought about by 
playing action video games are of importance in promoting visual plasticity.[18] That action video games modulate early sensory processing resulting in greater sensitivity to exogenous sensory inputs, [10] could also be an explanation for improvement in cognitive skills.

Reaction time is known to be affected by various factors like age, practice, fatigue and distractions.[19] In this study, a significant negative correlation was found between visual reaction time and duration of hours of playing video games. This might indicate that repeated video game playing results in training of the central nervous system in improving the ability to ignore and/or inhibit extraneous distracting stimuli. It could also be a result of traininginduced enhancement of performance which abound in the field of perceptual learning.[20] Conventional exercise training protocols as well as pranayamic practice are known to improve attention, reduce distractibility, reduce mental fatigability and induce alertness and arousal, especially to extraneous stimuli.[17,21]

Our study did not demonstrate any significant correlation between reaction time and body mass index in both study and control groups. However, adolescents spending more than 6-7 hours weekly on video games showed a trend towards higher body mass index than those who did not play at all. This finding could be attributed to a reduction in overall physical activity owing to more time spent in front of a screen.

As video-game playing has become a ubiquitous activity in today's society, it is worth considering its potential consequences on perceptual and motor skills, and that was the focus of this study. However, this study has a few limitations, especially in the age group and gender that was selected as well as the fact that a longitudinal study could not be undertaken. Moreover, one might argue that the reduced reaction time was what led to these adolescents excelling in, and therefore spending more time on computer games, and not the other way round. Such a premise can only be verified by a crossover cohort study.

\section{Conclusion}

This study concludes that playing action video games, by virtue of their very nature, enhances visual processing and thinking strategy in school children. It not only ensures better sensorimotor performance but also significantly improves cognitive skills of these individuals. Therefore, they exhibit faster reaction time than those who do not play video games. This faster reflex leads to better concentration, alertness, muscular co-ordination and improves performance in speed and accuracy tasks.
Such games, if used for training could lead to a better preparation for professions where faster reflexes and better hand-eye coordination are an asset. However, caution must be exercised, since excessive use of such games could have multiple deleterious effects as documented in earlier studies.

\section{Reference}

1. Beentjes JW, Koolstra CM, Marseille N, Voort TH. Children's use of different media: for how long and why? In: Livingstone S, Bovill M, editors. Children and their changing media environment: A European comparative study. Mahwah, NJ: Lawrence Erlbaum Associates; 2001:85-112.

2. Rideout VJ, Foehr UG, Roberts DF. Generation M2. Media in the lives of $8-18$ year-olds. A Kaiser Family Foundation Study. January 2010. Available at: https:// kaiserfamilyfoundation.files.wordpress.com/2013/01/8010. pdf. Accessed January 17, 2017.

3. Dworak M, Schierl T, Bruns T, Strüder HK. Impact of singular excessive computer game and television exposure on sleep patterns and memory performance of school-aged children. Pediatrics. 2007 Nov;120(5):978-85.

4. Chiriţă V, Chiriţă R, Stefănescu C, Chele G, Ilinca M. Computer use and addiction in Romanian children and teenagers--an observational study. Rev Med Chir Soc Med Nat Iasi. 2006 Jul-Sep;110(3):526-32.

5. Cao F, Su L, Liu T, Gao X. The relationship between impulsivity and internet addiction in a sample of Chinese adolescents. Eur J Psychiatry. 2007 Oct;22(7):466-71.

6. Chan PA, Rabinowitz T. A cross-sectional analysis of video games and attention deficit hyperactivity disorder symptoms in adolescents. Ann Gen Psychiatry. 2006;5:16.

7. Kim EJ, Namkoong $\mathrm{K}, \mathrm{Ku} \mathrm{T}$, Kim SJ. The relationship between online game addiction and aggression, self-control and narcissistic personality traits. Eur J Psychiatry. 2008 Apr;23(3):212-8.

8. Gentile DA, Lynch PJ, Linder JR, Walsh DA. The effects of violent video game habits on adolescent hostility, aggressive behaviors, and school performance. J Adolesc. 2004 Feb;27(1):5-22.

9. Hart GM, Johnson B, Stamm B et al. Effects of video games on adolescents and adults. Cyberpsychol Behav. 2009;12(1):63-5.

10. West GL, Stevens SA, Pun C, Pratt J. Visuospatial experience modulates attentional capture: evidence from action video game players. J Vis. 2008 Dec 22;8(16):13.1-9.

11. Green CS, Bavelier D. Action-video-game experience alters the spatial resolution of vision. Psychol Sci. 2007 Jan;18(1):88-94.

12. Boot WR, Kramer AF, Simons DJ, Fabiani M, Gratton G. The effects of video game playing on attention, memory, and executive control. Acta Psychologica. 2008 Nov;129(3):387-98. 
13. Griffith JL, Voloschin P, Gibb GD, Bailey JR. Differences in eye-hand motor coordination of video-game users and nonusers. Percept Mot Skills. 1983 Aug;57(1):155-8.

14. Dye MWG, Bavelier D. Differential development of visual attention skills in school-age children. Vision Res. 2010;50(4):452-9.

15. Mishra J, Zinni M, Bavelier D, Hillyard SA. Neural basis of superior performance of action videogame players in an attention-demanding task. J Neurosci. 2011;31(3):992-8.

16. Dye MWG, Green CS, Bavelier D. Increasing speed of processing with action video games. Curr Dir Psychol Sci. 2009;18(6):321-6.

17. Borker AS, Pednekar JR. Effect of Pranayam on visual and auditory reaction time. Indian J Physiol Pharmacol. 2003;47(2):229-30.
18. Achtman RL, Green CS, Bavelier D. Video games as a tool to train visual skills. Restor Neurol Neurosci. 2008;26(45):435-46.

19. Der G, Deary IJ. Age and sex differences in reaction time in adulthood: Results from the United Kingdom health and lifestyle survey. Psychol and Aging. 2006 March;21(1):62-73.

20. Green CS, Bavelier D. Action video game modifies visual selective attention. Nature. 2003 May 29;423(6939):534-7.

21. Mouelhi Guizani S, Bouzaouach I, Tenenbaum G, Ben Kheder A, Feki Y, Bouaziz M. Simple and choice reaction times under varying levels of physical load in high skilled fencers. J Sports Med Phys Fitness. 2006 Jun;46(2):344-51.

*Corresponding author:

Subhasis Das, Dept. of Physiology, Pondicherry Institute of Medical Sciences Ganapathychettikulam, Kalapet, Pondicherry - 605014, INDIA Phone: +919003547368

Email: subhasiscmc@gmail.com 